\title{
Infrared Spectral Studies of Copper-Containing Film on the Steel Sample
}

\author{
Sergey D. Pichugin, Vladimir N. Malyshev* \\ Department of Tribology and Repair Technology of Oil and Gas Equipment, Gubkin Russian State University of \\ Oil and Gas, Moscow, Russian \\ Email: vmal@inbox.ru
}

Received 25 December 2014; accepted 27 February 2015; published 9 March 2015

Copyright ( 2015 by authors and Scientific Research Publishing Inc.

This work is licensed under the Creative Commons Attribution International License (CC BY). http://creativecommons.org/licenses/by/4.0/

(c) () Open Access

\begin{abstract}
Infrared spectral studies of copper-containing film from steel sample (worn in pair with brass in glycerol) friction zone are performed in the study. The protective film formed by the interaction of the friction triad having functional groups typical for macromolecular compounds is shown.
\end{abstract}

\section{Keywords}

Copper-Containing Film, Functional Groups, Infrared Range, Friction

\section{Introduction}

The phenomenon of non-wear effect was discovered by Prof. Garkunov D.N. and Prof. Kragelsky I.V. as a result of studies conducted in the field of physical chemistry of contact interactions. A copper-containing film with a specific structure and properties is formed on friction surfaces while a pair of copper alloy-steel is being worn in glycerin. Such a film provides a low coefficient of friction and high wear resistance of mobile interfaces.

The concept of "third body" proposed by Kragelsky I.V. [1] more than 50 years ago and then more clearly expressed in its rule of the positive gradient of mechanical properties [2] (i.e. by increasing the shear resistance from the surface to the depth of volume) initially was considered mainly from the standpoint of mechanics.

The formation of this concept influenced studies performed by Kostetsky B.I. et al. [3] [4] on the theory of structural adaptability in friction materials. These studies were based on the generalized thermodynamic approach to the pair of friction as a system exhibiting spontaneous property adapt to the effects of external factors. Under this adaptation the changes are understood in the chemical and structural composition of the surface layer.

In Kostetsky B.I.'s works, the concept of "secondary structures" is used to determine the status of the transformed surface layer of the friction material. Originally under the secondary structures it was mainly understood

"Corresponding author. 
as oxide films, but then the concept has expanded and included any changes in the structure in the direction to facilitate the identification of optimal energy state of tribosystem [4]. In this sense, the term "secondary structure" covers virtually the same set of properties that the term "third body" covers.

Later Bushe N.A. [5] proposed a third approach to structural transformations on the frictional contact, which is similar in many respects to structural-energetically one (Kostecky B.I., Bershadsky L.I.), but has a number of unique features relating primarily to the fact that it focuses on the transformation of mechanical properties of the surface layer, role of initial heterogeneity of its properties in the final shaping of the surface film (e.g., the role of soft part of the structural component).

All of these three approaches are combined by the determining role of special state of the surface layer of materials tribosystem that allows allocating it as the specific element, regardless of its name "third body", "secondary structure", or "the film of frictional transfer". The works of many other professionals in the field of tribology also suggest that the specified condition has become an essential component of the basic models of tribological systems.

Synergetics has postulated that the behavior of system at the interface is controlled by the formation of mesophase. Therefore, the first time the concept of the so-called "third body" at the friction process is also detected in works of synergetic founders Nikolis G. and Prigogine I. [6]. Moreover, the tribological system differs from other systems by that it creates itself the conditions to the formation of the third body.

According to Ivanova V.S., Bushe N.A. and Gershman I.S.'s research [7], the managing parameter controlling the physical and chemical processes in the area of the third body is the self-heating temperature, which determines the critical points of friction. Critical values of the friction coefficient are associated uniquely with the critical temperature of self-heating. So you need to determine the dependence of the friction coefficient from the critical temperature of self-heating. This relationship corresponds to the transition from chaotic behavior orderly and allows managing the process of friction by introducing the feedback.

The most obvious example of so-called "third body" or "film of frictional transfer" formations in the friction process is the formation of films in friction pair copper alloy-steel in glycerol, composition of which according to numerous studies is not unambiguous and is still a matter of discussion.

So, some completed copper-containing film researches using modern methods of the analysis have shown its amorphous structure [8], presence of dielectric ability and polymer constitution [9]. However, practically there are no data of functional groups included copper-containing film in the technical literature. Thus, the aim of this paper is to perform the IR spectral studies of the film formed on the surfaces of friction pairs of copper alloysteel in glycerin. The method of IR spectroscopy is known to be widely used for qualitative and semi-quantitative analysis of substances in all aggregation states.

\section{Materials and Methods of Investigation}

Qualitative analysis is possible because of high individuality of IR spectra and the existence of the characteristic oscillations of some atomic groups. This circumstance allows providing definition of different components whose spectra do not depend on their concentration.

It is not possible to perform the IR spectroscopic studies of protective copper-containing film from the surface layers of antifriction alloy-steel pair worn in glycerin and in connection with this fact we have worn 20 pairs of samples of copper alloy-steel in glycerin (the specific load was $6 \mathrm{MPa}$ and the sliding speed is $1.0 \mathrm{~m} / \mathrm{s}$ on the friction path-2100 meters). The trials were conducted on the friction machine SMC-2 and scheme of friction was "block-roller". Roughness of the samples surface layers, specific loading and sliding speed were taken on the recommendations from the work [10]. The aim was to obtain low friction coefficient of mobile interfaces and effective copper-containing film on the surfaces of friction. The study provided with low purity glycerin, since, according to methodological experiments, the low purity also contributed to excitation of the non-wear effect.

Protective film was taken from the steel samples surface layers by sharp razor and thus the products of triad friction interaction were obtained and had a size of approximately five matchbox heads.

In order to obtain reflectance spectrums, IR spectroscopic studies were performed on the spectrometer of the company "Bruker" (Germany). Copper-containing film from the steel sample was studied in the wavelength range $3800-600 \mathrm{~cm}^{-1}$. The infrared region of the spectrum covers reflections caused almost all the groups of organic compounds in this range. 


\section{Results of Investigation and Discussion}

The experimentally obtained wave's length from copper-containing film was compared with published data for identification of the discovered functional groups [11]. The IR spectrum obtained from metal-containing film formed on the surface of the friction of steel sample in case of wear in a pair of brass 63 in glycerin is shown in Figure 1.

The investigation was conducted with already framed film, in homogeneously disposed on a surface of the sample. The aim of the investigation is to prove presence of high-molecular compounds in the film structure and clarify in more detail the composition of the film. First spectrum has been obtained at the 120 unit's level of transmittance. Then, for verifying data, two approximately identical spectra have been obtained.

The presence of band reflections with low intensity $3500-3000 \mathrm{~cm}^{-1}$ could be noted. This intensity corresponds to the stretching vibrations of the $\mathrm{OH}$ group with molecular hydrogen bond. Reflection bands (3000 $2800 \mathrm{~cm}^{-1}$ ) characterizing the stretching vibrations of $\mathrm{CH}$ in $\mathrm{CH}_{2}$ and $\mathrm{CH}_{3}$ groups are also presented. Reflection bands $\left(1800-1400 \mathrm{~cm}^{-1}\right)$ indicating the presence of the atmospheric water in the product are visible in the IR spectrum. Additionally, the presence of a $\mathrm{CO}_{2}$ group (band reflection $2350 \mathrm{~cm}^{-1}$ ) is uncovered. The presence of the atmospheric water and $\mathrm{CO}_{2}$ groups are associated with the air's atmosphere.

Considered copper-containing film IR spectra (film formed while interaction of the friction triad) allow to note the presence of reflection bands in the field of $1200-1000 \mathrm{~cm}^{-1}$ which are connected with the presence of the C-O-C-O-C structures in the film's composition. Moreover, reflection bands in the field of $900-800 \mathrm{~cm}^{-1}$ are detected. It is probably connected with the presence of the third substituted $\mathrm{C}=\mathrm{C}$ connections in the film's composition.

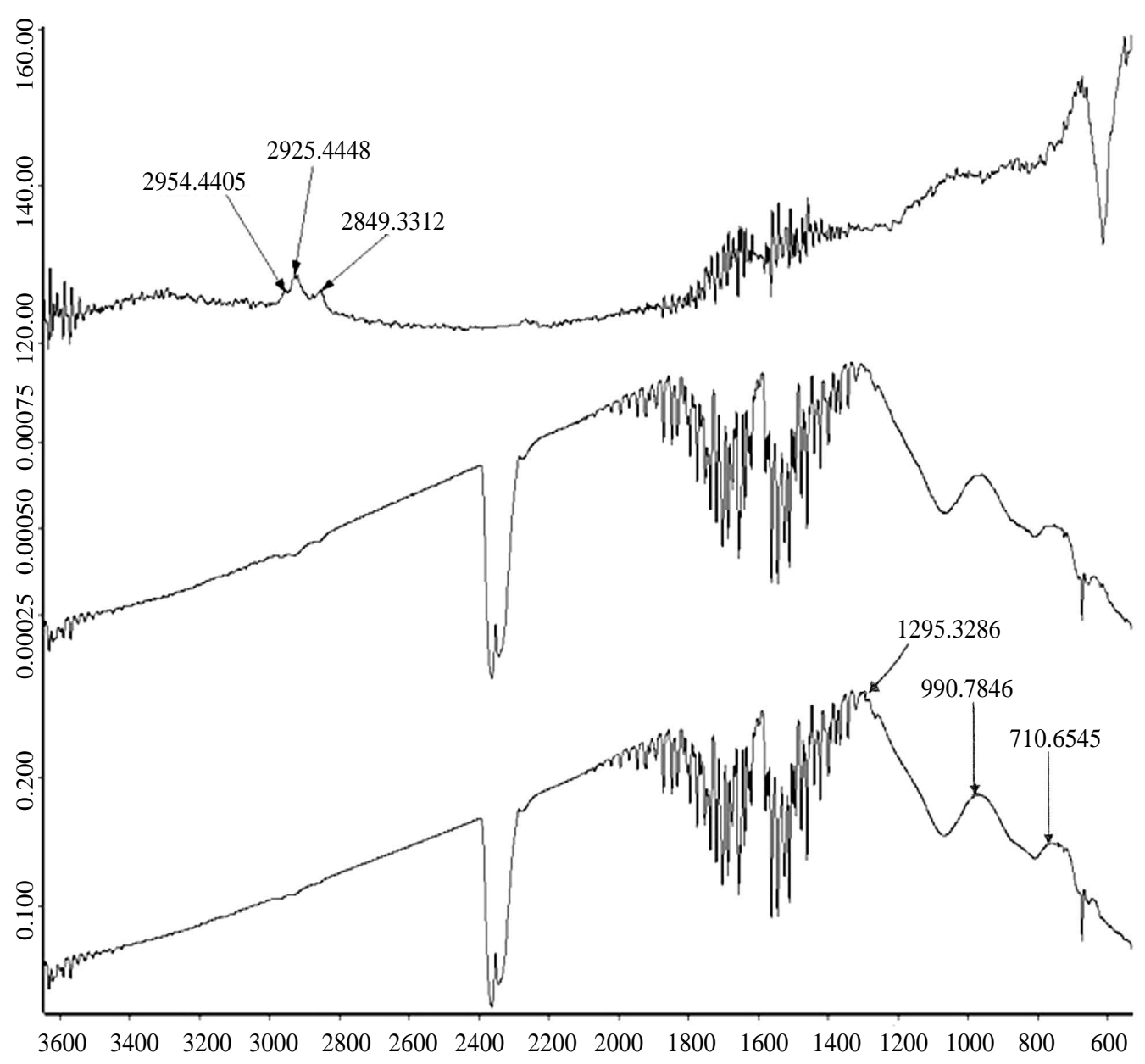

Figure 1. IR spectrum research of copper-containing film from steel sample, worn in pair with brass (L63) in glycerin. The figure illustrates the function: $f=I(k)$, where $k$ is wave number and $I$ is transmittance. 
The presences of the absorption bands $\left(3500-3000 \mathrm{~cm}^{-1}\right.$ ) were shown by IR spectroscopic studies before the work in a copper alloy-steel pair. These bands correspond to the valence vibrations of the $\mathrm{OH}$ group with intermolecular hydrogen bond. The peaks in the field of $3000-2800 \mathrm{~cm}^{-1}$, characterizing the stretching vibrations of $\mathrm{CH}$ in $\mathrm{CH}_{2}$ and $\mathrm{CH}_{3}$ groups, were also detected. Thus, the peaks indicated by arrows in Figure 1 correspond to methyl and methylene groups. Absorption bands $\left(1640 \mathrm{~cm}^{-1}\right.$ and $\left.112 \mathrm{~cm}^{-1}\right)$ are found in the IR spectrum of glycerin. These bands correspond to the deformation pressure fluctuations $\mathrm{H}-\mathrm{OH}$ from the water and the $\mathrm{OH}$ alcohol group. In conformity with the nonequilibrium processes of thermodynamics, new structures (copper or high molecular films) occur in "open systems" only, which are able to exchange matter and energy with the environment. The presence of side compounds (for example, atmospheric water) only confirms the "open" nature of the system studied in the research.

The IR spectrum data from the copper-containing film (formed in friction zone of steel sample when working in pair with a copper alloy in glycerin) were compared with data from the IR spectrum of glycerin. This comparison showed that in mentioned cases there was a group of $\mathrm{OH}$ with intermolecular hydrogen bond, as well as the valence $\mathrm{CH}$ in $\mathrm{CH}_{2}$ and $\mathrm{CH}_{3}$ groups. However, the intensity of these bands in glycerin is more than the similar reflection bands in IR spectrum obtained from the copper-containing film.

The IR spectrum studies of copper-containing film formed in the steel sample friction zone when wearing brass-steel pair on SMC-2 friction machine using block-roller in glycerin scheme allows making a conclusion that there are reflection bands in the field of $1300-700 \mathrm{~cm}^{-1}$ in IR spectrum obtained from the copper-containing film. The dispersed nature of these bands is typical for high-molecular organic compounds.

\section{Conclusion}

Thus, the protective film on the surfaces of friction formed in case of friction pairs outwearing under conditions of non-wear effect is a high molecular organic compound. This fact is still not registered by anybody and thus, in essence, is an innovative discovery.

\section{References}

[1] Kragelsky, I.V. (1968) Friction and Wear. Mashinostroenie, Moscow (in Russian).

[2] Kragelsky, I.V., Kombalov, V.S. and Dobychin, V.N. (1980) The Bases of Calculations on Friction and Wear. Mashinostroenie, Moscow (in Russian).

[3] Kostetsky, B.I. (1970) Friction, Lubrication and Wear in Machines. Tekhnika, Kiev (in Russian).

[4] Kostetsky, B.I., Natanson, M.E. and Bershadsky, L.I. (1972) Mechanochemical Processes in the Boundary Lubrication. Nauka, Moscow (in Russian).

[5] Bushe, N.A. and Kopytko, V.S. (1981) Compatibility of the Rubbing Surfaces. Nauka, Moscow (in Russian).

[6] Nicolis, G. and Prigogine, I. (1989) Exploring Complexity: An Introduction. W.H. Freeman and Company, New York.

[7] Ivanova, V.S., Bushe, N.A. and Gershman, I.S. (1997) Structural Adaptability at Friction as a Process of Self-Organization. Friction and Wear, 18, 74-79.

[8] Pichugin, V.F. and Scherbinin, V.M. (2009) Friction Areas of Copper, Aluminum Alloy-Steel Pairs Worn in Glycerin. Friction and Lubrication in Machines and Mechanisms, 9, 27-33 (in Russian).

[9] Kuzharov, A.S., Burlakova, V.E., Marchak R.I., et al. (1997) Tunneling Microscopy of the Tribosystem Copper-Glycerin-Steel Friction Surfaces. Abstracts for the 5th International Scientific-Technical Conference on the Dynamics of Technological Systems, Rostov-on-Don, Vol. 2, 122-123 (in Russian).

[10] Litvinov, V.N., Michin, N.M. and Myshkin, N.K. (1979) Physical and Chemical Mechanics of Selective Transfer in Friction. Science, Moscow (in Russian).

[11] Bellali, L. (1963) Infrared Complex Molecules Spectrums. Publishing House of Foreign Literature, Moscow (in Russian). 